\title{
Walkability Assessment for Elderly Citizens and People with Disabilities
}

\author{
Wonho Suh, Bo Sung Kim, and Youngjin Yurk,
}

\begin{abstract}
Number of elderly citizens and people with disability is increasing and there are growing needs for walkability assessment for them. Unbiased assessment about the pedestrian facility to better accommodate elderly citizens and people with disability will help local governments identify the problems and improve their facility. This paper provides information on the current infrastructure monitoring program to improve walkability for elderly citizens and people with disabilities. Also, this paper investigates the influencing factors in walkability assessment for elderly citizens and people with disability based on the field data. From the field data, it was found that pedestrian environments were affecting manual wheelchair users, while electric wheelchair users showed significantly lower level of correlations. Although this paper only provided results from limited field data, it is believed that this paper provided a framework for the data collection to identify influencing factors for elderly citizens and people with disability. More comprehensive data collection and statistical analysis will help to improve the walkability assessment process for elderly citizens and people with disability.
\end{abstract}

Index Terms-Elderly pedestrian, pedestrian environment, pedestrian with disability, walkability, walkability assessment.

\section{INTRODUCTION}

Population is aging in most countries and there are growing concerns about the current infrastructure which has not been designed for elderly citizens and people with disability.

According to National Institute on Aging, there were 335 million children in the 0-4 age group and just 131 million people ages 65 and over in 1950. Based on the estimates of United Nations Population Division, there are 642 million persons ages $0-4$ and 523 million ages 65 and over in mid2010. These changing demographics are correlated with the average life expectancy and decline of birth rates [1].

The fact that the numbers and percentages of elderly citizens and people with disability are increasing and this trend is expected to continue for a considerable time poses many challenges to civil engineers who need to design and maintain infrastructure to ensure the quality of living.

Many aspects of infrastructure have been designed for average people in that time period. However, the average people will likely be over 65 and over and with higher

Manuscript received July 31, 2016; revised October 21, 2016. This work was supported in part by This research was supported by a research grant (Research Project 079209) from Transportation \& Logistics Research Program funded by Ministry of Land, Infrastructure and Transport Affairs of Korean government.

The authors are with Hanyang University ERICA Campus, Ansan, South Korea (e-mail: wonhosuh@hanyang.ac.kr, chen2@hanyang.ac.kr, dudwls0688@naver.com). chances of disability. Many of current infrastructure design fail to accommodate elderly citizens and people with disability.

Characteristics of elderly citizens and people with disability include reduced range, slowed walking time, vision problems, slowed reaction times, and difficulty in uphill walking [2]-[4].

However, elderly citizens and people with disability are becoming more independent in terms of living and there are growing needs for improved mobility. Recently, significant improvement took place in personal mobility including personal electric wheelchair and smart phone based applications to provide important sources of information [2]-[4].

To provide better mobility options to elderly citizens and people with disability, it is crucial to develop a monitoring program for walking environments. In this program, identification of the issues and providing solutions need to be included. This paper provides information on the current infrastructure monitoring program to improve walkability for elderly citizens and people with disabilities. Also, this paper investigates the influencing factors in walkability assessment for elderly citizens and people with disability based on the field data.

\section{WALKABILITY ASSESSMENT}

Walkability refers to a measure how safe and friendly an area is to walking. Many factors are associated with walkability. Build environments such as sidewalks, crossings, lighting, vehicle speed passing by, and surface pavement condition influence walkability [2]-[11].

Many countries try to find ways to provide better walkability to people including elderly citizens and people with disability [5]-[8]. For example, the Americans with Disabilities Act (ADA) states that "A public entity may not deny the benefits of its programs, activities, and services to individuals with disabilities because its facilities are inaccessible.

A public entity's services, programs, or activities, when viewed in their entirety, must be readily accessible to and usable by individuals with disabilities. This standard, known as "program accessibility," applies to all existing facilities of a public entity. Public entities, however, are not necessarily required to make each of their existing facilities accessible" [2].

Also, the Americans with Disabilities Act provides a self-evaluation tool to identify barriers that prevents persons with disabilities from access. Also, there is a widely used walkability audit tool, called PERS (Pedestrian Environment 
Review System) which has been used extensively in the UK [4]. In this section, ADA self-evaluation and PERS are briefly reviewed.

\section{A. ADA Self Evaluation}

The Americans with Disabilities Act (ADA) of 1990 is a civil rights statute that prohibits discrimination against people who have disabilities [2]. There are five separate Titles, or sections, of the Act that cover different aspects of potential discrimination. Title II of the Americans with Disabilities Act (ADA) prohibits discrimination against qualified individuals with disabilities by public entities. Activities covered include all services, programs and activities offered by the public entity, all aspects of employment, services carried out by contractors, all activities of the local legislative and judicial branches and public transportation. Designing and constructing facilities for public use that are not accessible by people with disabilities constitutes discrimination [2].

State and local government and public entities or agencies are required to perform self-evaluations of their current facilities, relative to the accessibility requirements of the current ADA accessibility standards.

Per the Act, public agencies are required to develop a Program Access Plan (also called a Transition Plan) to address any deficiencies that exist and to update the Plan periodically.

Objectives of this plan are to identify barriers limiting the accessibility of facilities to individuals with disabilities, describe the methods to be used to address those barriers, provide a financial schedule for making modifications, and identify the public officials responsible for Plan implementation.

For example, evaluations for pedestrian access routes and curb ramps utilize a standard of at least 4 feet wide with a maximum cross slope of $2 \%$ with transition markings to ensure accessibility in public right-of-way. Pedestrian access routes and curb ramps are evaluated visually for potential accessibility deficiencies. Fig. 1 and Fig. 2 show examples of ADA self-evaluation of pedestrian facilities in the public Right-of-Way [3].

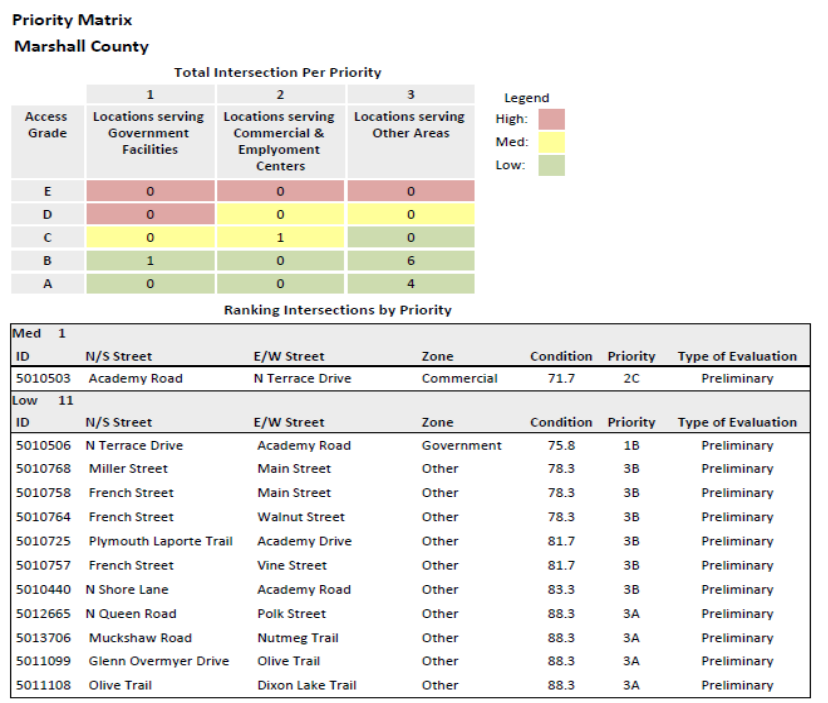

Fig. 1. ADA self evaluation priority matrix example [3].

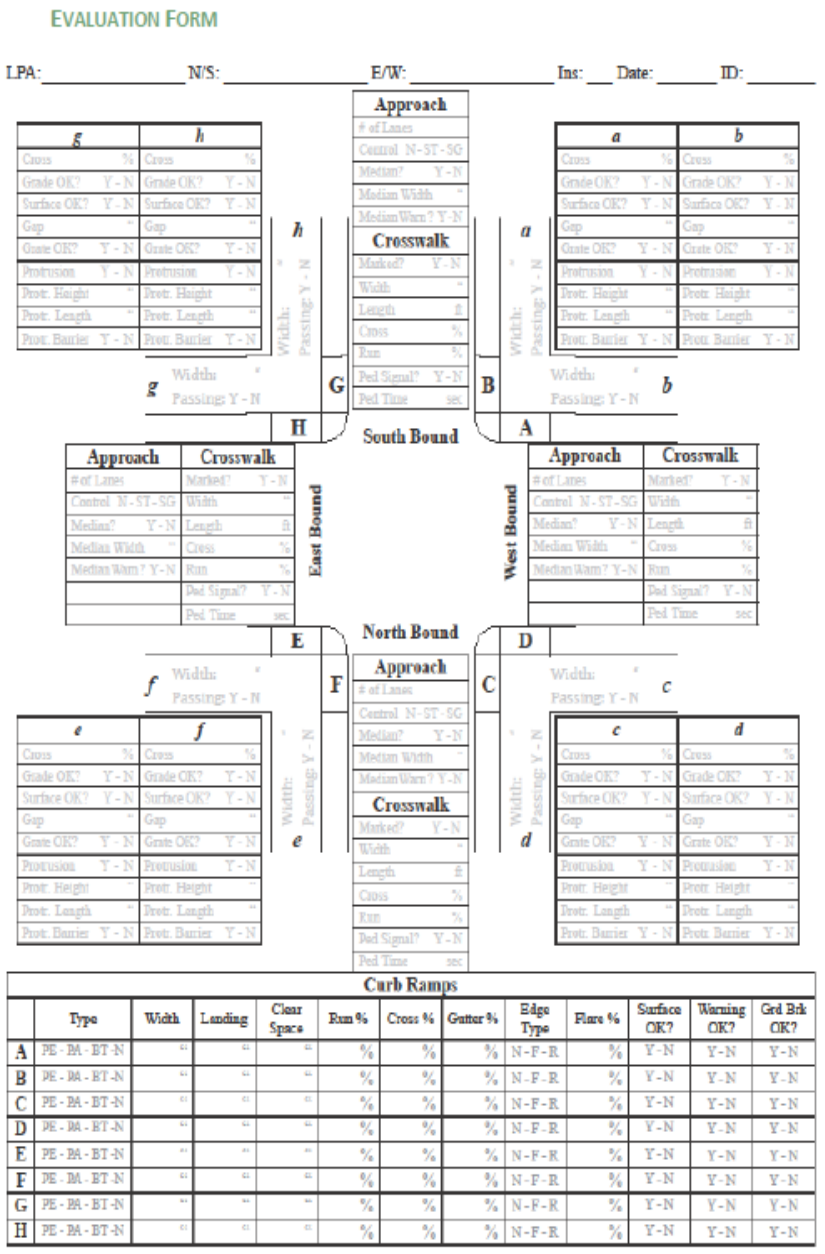

Fig. 2. ADA self-evaluation example of pedestrian facilities in the public right-of-way [3].

\section{B. Pedestrian Environment Review System}

Pedestrian Environment Review System (PERs), a walking audit tool, has been developed by TRL (Transport Research Laboratory) in co-operation with Transport for London [4]. PERS review links (footway, footpath or highway), crossings (designated or undesignated crossing where a pedestrian route intersects with a highway. side road junctions can also be considered as crossings), routes (comprised of links, crossings and other PERS pedestrian environments to form a trip from start to finish), public transport waiting areas (designated area where people are required to wait in order to use public transport, such as bus and train stops), interchange spaces (areas around and between public transport stops or termini allowing people to change between transport modes), public spaces [4].

PERS utilizes both quantitative and qualitative methods to review pedestrian environments. For example, factors regarding pedestrian environment, such as footway widths and dropped curb gradients can be reviewed as quantitative values, while elements such as personal safety and quality of the environment can be considered as qualitative values. The PERS scoring system utilizes ranges from -3 to +3 , where 0 is an average score. Fig. 3 demonstrates PERS assessment result [4]. 


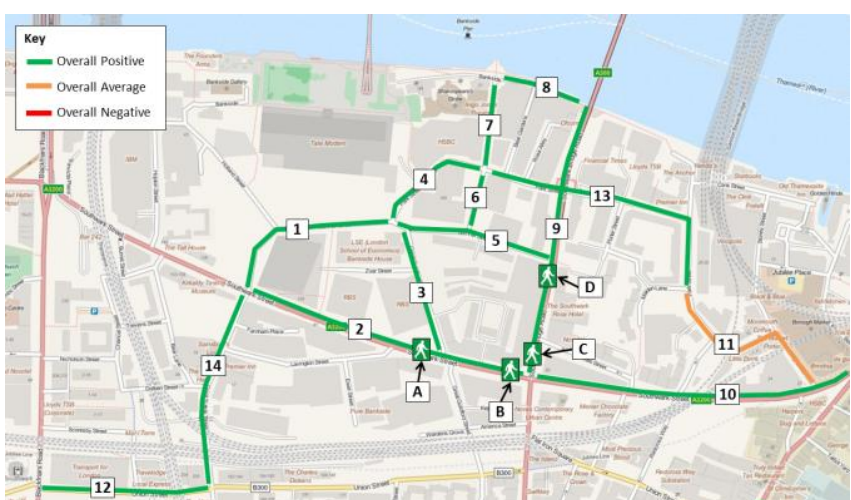

Fig. 3. PERS score rating example [4].

\section{DATA COLLECTION FOR WALKABILITY ASSESSMENT}

\section{A. Objective}

Walkability assessment is one way to measure walkability for elderly citizens and people with disability. From the assessment it is possible to compare walkability from location to location and propose specific recommendations to improve walkability of target area.

For comprehensive evaluation, it is essential to identify the influential factors for the level of service for elderly citizens and people with disability. This paper aims to investigate the parameters to influence elderly citizens and people with disability based on the field data.

\section{B. Data Collection}

For the preliminary field data collection, factors which can potentially influence the pedestrian level of service of elderly citizens and people with disability are identified. These factors include accessibility (yes or no), sidewalk width (meter), pavement conditions (above average, average, or below average), crosswalk proximity, sidewalk connectivity, vehicle conflict, pedestrian volume (crowdness), and lighting availability.

Also, it is assumed that different characteristics of pedestrian (for example, level of disability or type of disability) influence the factors. Therefore, data are collected for people with blindness, people using manual wheelchair, and people using electric wheelchair.

During the data collection, speed data, heart beat data and sound data were collected and compared with pedestrian facility data obtained by using GPS data. Fig. 4 represents devices used for the data collection. Fig. 5 shows the actual data collection for electric wheelchair users.

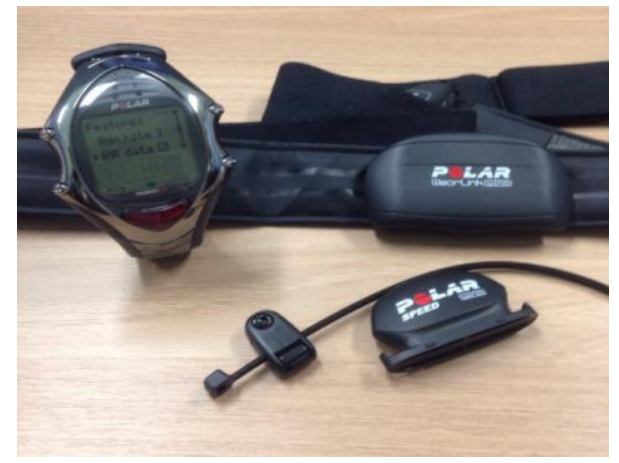

Fig. 4. Data collection devices.

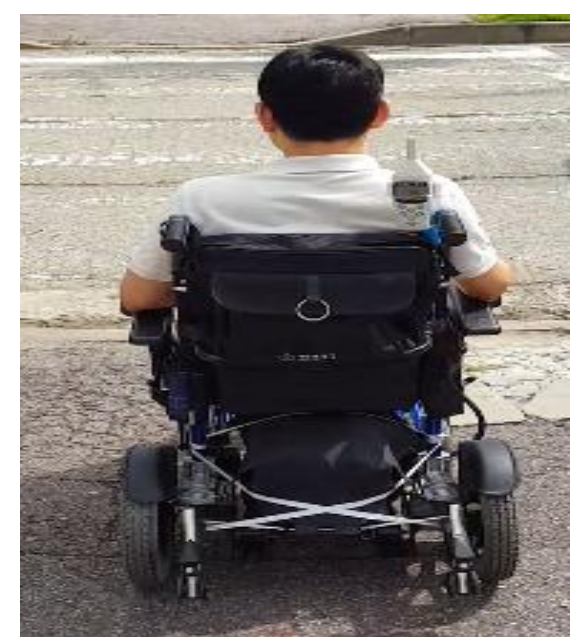

Fig. 5. Data collection for electric wheelchair users.

\section{Preliminary Results}

As previously mentioned, data were collected for people with blindness, people using manual wheelchair, and people using electric wheelchair. For each group, speed data, heart beat data and sound data were collected and compared with pedestrian facility data obtained by using GPS data.

As expected, it was found that heart beats were increasing for the wheel chair users. As shown in Fig. 6, there is a gradual uptrend in heart beat with the data collection time. Also, it was observed that heart beat went up significantly when the subject was on uphill. Heart beat came down when the subject stopped at the end of data collection.

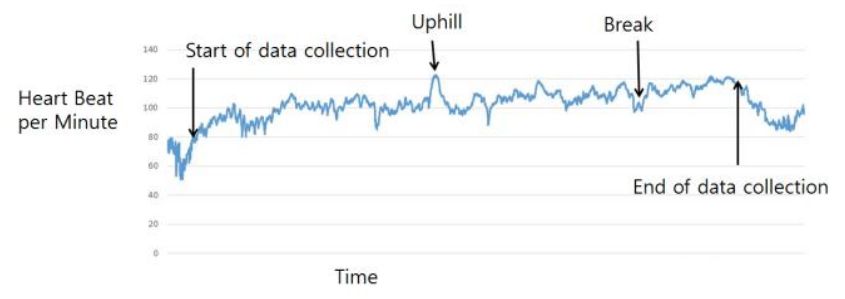

Fig. 6. Heart beat data for manual wheelchair users.

For the electric wheel chair users, no correlation was found between heart beat and other factors including data collection time, wheelchair operating speed, slope of sidewalk, and noise level (Fig. 7).

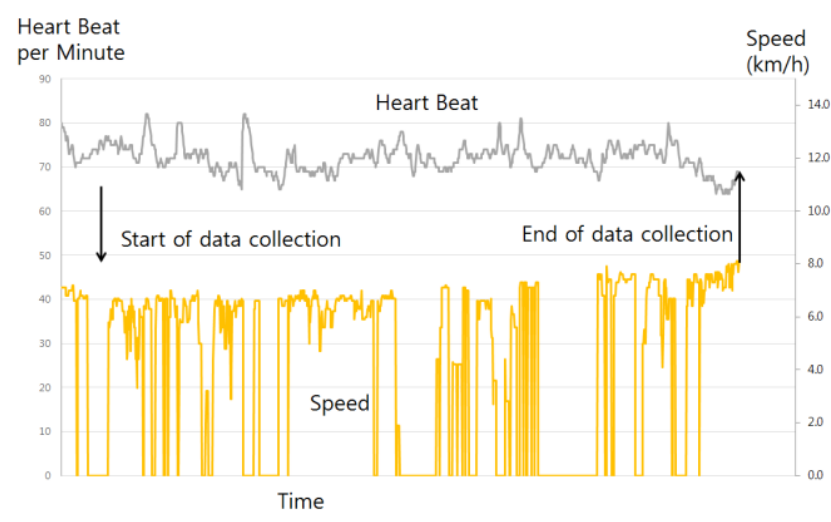

Fig. 7. Heart beat and operating speed data for electric wheelchair users. 


\section{CONCLUSION}

Conventional methods to measure level of service of pedestrians are similar with the level of service assessment for vehicles on the road utilizing number of pedestrians and infrastructure characteristics. However, it is believed that the level of service assessment for elderly citizens and people with disability is more complicated and more complex factors are involved.

This paper aimed to investigate the factors in walkability assessment for elderly citizens and people with disability. Since elderly citizens and people with disability have different characteristics in terms of walking capability, it is important to understand the factors and their impact on the level of service for elderly citizens and people with disability.

Since each disability group is different from other groups, the factors should be carefully selected and measured. These factors would include not only various quantitative variables but also qualitative variables. Also, elderly citizens and people with disability are expected to be more sensitive to safety, personal security, and personal comfort factors compared with average pedestrians.

Although this paper only provided a preliminary result from the limited field data, it is believed that this paper provided a framework for the data collection to identify influencing factors for elderly citizens and people with disability. More comprehensive data collection and statistical analysis will help to improve the walkability assessment process for elderly citizens and people with disability.

\section{REFERENCES}

[1] C. Haub, World Population Aging, Population Reference Bureau, Washington, D.C., 2011.

[2] The Americans with Disabilities Act, United States Department of Labor, Washington, D.C., 2010.

[3] Americans with Disabilities Act Transition Plan: Pedestrian Facilities in the Public Right-of-Way, Marshall County, 2012.

[4] Pedestrian Environment Review System (PERS) Report, London, U.K., 2014.

[5] J. Kim, B. Koo, S. Suh, and W. Suh, "Integration of BIM and GIS for formal representation of walkability for safe routes to school programs," KSCE Journal of Civil Engineering, vol. 20, no. 5, pp. 1669-1675, 2016.

[6] D. Bassett, J. Pucher, R. Buehler, D. Thompson, and S. Crouter, "Walking, cycling, and obesity rates in Europe, North America, and Australia," Journal of Physical Activity and Health, vol. 5, pp. 795-814, 2008.

[7] M. Boarnet, M. Greenwald and T. McMillan, "Walking, urban design, and health: Toward a Cost-Benefit analysis framework," Journal of Planning Education and Research, vol. 27, no. 3, pp. 341-358, 2008.

[8] T. Litman, "You can get there from here: Evaluating transportation system diversity," Transportation Research Record, pp. 32-41, 2001.

[9] T. Litman, "Measuring transportation: Traffic, mobility and accessibility," ITE Journal, vol. 73, no. 10, pp. 28-32, 2003.

[10] J. Pucher and L. Dijkstra, "Making walking and cycling safer: Lessons from Europe," Transportation Quarterly, vol. 54, no. 3, 2000.
[11] J. Pucher and L. Dijkstra, "Promoting safe walking and biking to improve public health: Lessons from the Netherlands and Germany," American Journal of Public Health, vol. 93, no. 9, pp. 1509-1516, 2003.

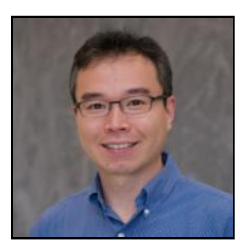

Wonho Suh is an assistant professor at the Department of Transportation and Logistics Engineering at Hanyang University in South Korea. He obtained his B.S. in Civil Engineering from Seoul National University (1998), his M.S. from Seoul National University (2000) and Georgia Institute of Technology (2008), and his Ph.D. from Georgia Institute of Technology (2012).

After obtaining his M.S from Seoul National University, he worked as a transportation engineer for more than five years at Yooshin Corporation in Seoul, Korea. He also worked as a research faculty at Georgia Institute of Technology from 2011 to 2013 . He has conducted numerous traffic impact studies, traffic operation evaluations, traffic demand analysis, and traffic safety studies. His primary teaching and research interests are in traffic operations and design, specializing in traffic simulation, highway geometric design, and traffic operations.

Prof. Suh is a member of Transportation Research Board, Korean Society of Transportation, Korean Society of Road Engineers, and Korea Institute of Intelligent Transport Systems. Also, he is an advisory committee member of International Multi-Conference on Engineering and Technology Innovation and International Conference on Advanced Technology Innovation. $\mathrm{He}$ received PTV (VISSIM) America's User Group Meeting Best Abstract Award at 2011 PTV Vision Users Group Meeting and Best Paper Award at Principles of Advanced and Distributed Simulation Conference in 2007.

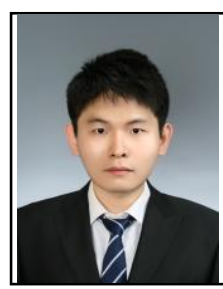

Bo Sung Kim is a Ph.D. student at the Department of Transportation and Logistics Engineering at Hanyang University in South Korea. He received his B.S. and M.S. from Hanyang University in 2010 and 2012, respectively. He is currently pursuing his $\mathrm{Ph} . \mathrm{D}$. degree.

His research interests are pedestrian environment assessment, pedestrian facility evaluation, and traffic simulation.

Mr. Kim is a member of Korean Society of Transportation and Korea Institute of Intelligent Transport Systems.

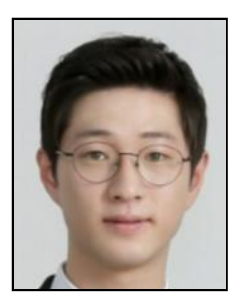

Youngjin Yurk is a graduate research assistant at the Department of Transportation and Logistics Engineering at Hanyang University. He received his B.S. from Hanyang University in 2016 and is currently pursuing his MS degree.

His research interests are pedestrian facility design, transportation system evaluation, and pedestrian assistance system development.

Mr. Yurk is a member of Korean Society of Transportation and Korea Institute of Intelligent Transport Systems. 